\title{
Assessment of soil microbial functional diversity: land use and soil properties affect CLPP-MicroResp and enzymes responses
}

\author{
M.C. Moscatelli ${ }^{a}$, L. Secondi ${ }^{a}$, R. Marabottini ${ }^{a}$, R. Papp ${ }^{a}$, S.R. Stazi ${ }^{a}$, E. Mania ${ }^{b}$, S. Marinari ${ }^{a, *}$ \\ ${ }^{\text {a }}$ Dept. for Innovation in Biological, Agrofood and Forest Systems (DIBAF), University of Tuscia, Viterbo, Italy \\ b Department of Agricultural and Forest Sciences (DISAFA), University of Torino, Torino, Italy
}

\section{A R T I C L E I N F O}

\section{Keywords:}

Microbial processes

Shannon diversity index

Soil properties

\begin{abstract}
A B S T R A C T
The assessment of microbial functional diversity is an important indicator of soil quality. Different methodological approaches are currently used; among them are enzyme activities (EA) and CLPP (community level physiological profile) techniques (e.g. MicroResp ${ }^{\mathrm{TM}}$, MR). The aims of the study were: $i$ ) to assess the efficacy of both methods in capturing differences among various land use categories when different levels of selected explanatory variables such as, total organic carbon (TOC) and $\mathrm{pH}$ are considered, and ii) to explore, through a quantile regression approach, the possible relationships between each of the two methods with land use category, TOC and $\mathrm{pH}$. The Shannon diversity index (H'), calculated from EA and MR data, was chosen as a synthetic index deriving from the same mathematical model. The quantile regression model (QRM), the Kruskal-Wallis and Spearman rank correlation tests were performed.

Enzyme activities and MicroResp were reliable ecological indicators to assess soil microbial functional diversity. No correlation was found between the diversity indexes, H'EA and H'MR; it was therefore supposed that the two methods may target complementary components of microbial functional diversity. Both methods were effective in capturing differences among various land use categories, in particular H'MR in soils with low TOC content $(<1.5 \%)$. Moreover, the QRM approach allowed a more detailed analysis along the distribution of the diversity indexes (H'EA and H'MR) indicating that H'EA was more dependent on the selected variables.
\end{abstract}

\section{Introduction}

The links between ecosystem functioning and levels of soil biodiversity have been the focus of the recent scientific literature (DelgadoBaquerizo et al., 2016; Creamer et al., 2016b; Griffiths et al., 2016; Nannipieri et al., 2003). The first authors provided evidence that loss in microbial diversity will likely reduce multiple ecosystem functions thus negatively impacting the provision of ecosystem services. Adhikari and Hartemink (2016) claimed for new insights into soil microbial diversity and their role in soil functional variability. Since up to $80 / 90 \%$ of soil functions, from humification to mineralization, is microbially-mediated, the diversification of soil microrganisms in terms of structure and/ or activity is essential to maintain functioning of terrestrial ecosystems (Pereira Silva et al., 2013).

Microbial functional diversity is defined as "the sum of the ecological processes, and/or capacity to use different substrates developed by the organisms of a community" (Insam et al., 1989). Emmerling et al. (2002) and Wellington et al. (2003) report that if microbial genetic diversity assesses a latent diversity, which may not be expressed, functional diversity is related to the actual activities resulting from that potential so that "functional rather than taxonomic diversity may provide greater insight to microbial roles in ecosystems" (Zak et al., 1994).

Over the last 10 years, the scientific literature provided a great number of papers aimed to assess microbial functional diversity as an important ecological indicator to monitor and assess soil quality changes in different pedoclimatic conditions, land uses and human pressure levels (e.g. management practices) (Bardgett and van der Putten, 2014; Griffiths et al., 2016).

To measure the activity and diversity of the microbial community a number of methods can be applied, to cite few of the most common approaches: (i) catabolic activity investigated by Biolog ${ }^{\mathrm{TM}}$-plates (Garland and Mills, 1991; Rutgers et al., 2016), (ii) respiration of different substrates as investigated by the MicroResp ${ }^{\mathrm{TM}}$ method (Campbell et al., 2003; Chapman et al., 2007; Creamer et al., 2016a) and (iii) enzyme activities (Nannipieri et al., 2012; Hendriksen et al., 2016).

Although all methodological approaches are reliable and sensitive, few studies have aimed to understand their effectiveness to discriminate microbial functional diversity in relation to soil organic $\mathrm{C}$ and

\footnotetext{
* Corresponding author.

E-mail address: marinari@unitus.it (S. Marinari).
} 
$\mathrm{pH}$ as the main properties being affected by land use and management practices, anthropic impact and other pedogenic factors. To achieve this goal, a large number of case studies covering different land use categories is necessary. In this study, about 200 measurements of microbial functional diversity obtained over a broad spectrum of key soil properties and across different land uses and management, were selected. Furthermore, microbial functional diversity obtained through enzyme activities (EA) and CLPP-MicroResp (MR), was synthetically represented by the Shannon index $\left(\mathrm{H}^{\prime}\right)$ that transforms the obtained results to a comparable range of values deriving from the same mathematical model. The Shannon index is a comprehensive indicator of microbial species, individual numbers and evenness, or distribution of the enzyme activities and is influenced by richness of community species (Bending et al., 2002; Li et al., 2007).

The aim of the present study was therefore to: $i$ ) assess the efficacy of both methods in capturing differences among the different land use categories when different levels of $\mathrm{pH}$ and TOC are considered, ii) explore, through a quantile regression approach, the possible relationships between each of the two methods and selected explanatory variables (TOC, land use category, $\mathrm{pH}$ ).

\section{Materials and methods}

\subsection{Experimental design, sites and soil categories}

The results presented in this paper have been obtained performing additional statistical analyses on data collected in the Laboratory of Chemistry and Biochemistry, University of Tuscia, Viterbo, Italy during the last 6 years (2010-2016). Microbial functional diversity was measured, by means of enzyme activities and CLPP-MicroResp ${ }^{\mathrm{TM}}$ technique, in a wide range of soils analysed within different research projects. Most of the sampling sites are located within the Mediterranean climatic area. Other climatic areas are the monsoon one for the Bangladesh case study, the temperate one for Switzerland, oceanic for United Kingdom and boreal for Sweden. All soils represent a broad spectrum of key soil properties across different land use categories, wide range of soil $\mathrm{pH}$ and soil organic carbon content (TOC) (Table 1).

The soils were related to 15 case studies, each one including different treatments, with the aim to separate diverse land uses and/or specific conditions. For this purpose, three groups were identified: $F$ (forest soils, 4 case studies), A (agricultural soils, 5 case studies) and EC (extreme conditions, 6 case studies). The case studies related to forest soils (F) included different management practices, lithological substrates, afforestation and chronosequences. The soils under agricultural land use (A) were characterized by different managements and/or agricultural practices such as: organic, biodynamic, conventional cropping systems, tillage/no tillage and natural green cover/no cover. The third category (EC) included soils with peculiar characteristics due to either pedo-climatic conditions (saline environments, natural arsenic contamination in rice paddies and highly calcareous soils) or to heavy anthropic impact (thallium contamination, a multi-element contaminated dump, arsenic contaminated mine) (Table 1).

\subsection{Soil sampling}

All soils were sampled at $0-20 \mathrm{~cm}$ depth during the dry season (spring/summer), air dried, sieved at 2-mm mesh and preserved at room temperature. Then, prior to biochemical analyses, soil moisture content of air dried samples was adjusted to $60 \%$ of their water holding capacity and soils were re-conditioned for 10 days.

\subsection{Soil analyses and methodologies}

The total organic carbon (TOC) was determined by combustion of sample in an oxygen-enriched atmosphere and detection and quantification of $\mathrm{CO}_{2}$ evolved by infrared detector using the Shimadzu TOC

\section{首}

$+\infty \pm N$

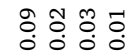

$\begin{array}{lll}2 & 0 \\ +1 & +1 & +1\end{array}$

ㅎํㅇㅇํㅇㅇㅜ

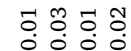

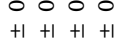

คิํํㅇํㅇ

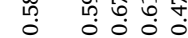

ㅂ.

$+1+1+1+1+1$

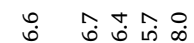

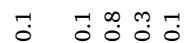

$+1+1+1+1$

म

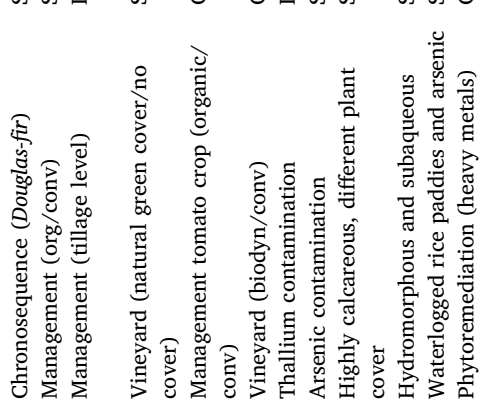


VCSH analyzer while soil $\mathrm{pH}$ was measured on sieved soil suspended in a solution of deionised water in 1:2.5 ratio $(\mathrm{w} / \mathrm{v})$. The $\mathrm{pH}$ was measured in the supernatant with a $\mathrm{pH}$ meter ( $\mathrm{pH} 211$, Hanna Instruments).

A total of 196 values of microbial functional diversity, assessed by means of enzyme activities and CLPP-MicroResp, were used for this study (Table 1). Enzymes were measured following Marx et al. (2001) using fluorogenic methylumbelliferyl (MUF)-substrates. Soils were analysed for cellobiohydrolase, $\beta$-1,4-glucosidase, $\alpha$-1,4-glucosidase, $\beta$ $N$-acetyl-glucosaminidase, $\beta-1,4$-xylosidase, acid-phosphatase, arylsulphatases and butyrate esterase which is considered a proxy of endocellular activity (Wittmann et al., 2004). The relative fluorogenic substrates, prepared with acetate buffer $0.5 \mathrm{M} \mathrm{pH} 5.5$, were: 4-MUF- $\beta$-Dcellobioside, 4-MUF- $\beta$-D-glucoside, 4-MUF- $N$-acetyl- $\beta$-glucosaminide, 4MUF- $\alpha$-D-glucoside, 4-MUF-phosphate, 4-MUF-7- $\beta$-D-xyloside, 4-MUFsulphate and 4-MUF-butyrate. Fluorescence (excitation $360 \mathrm{~nm}$, emission $450 \mathrm{~nm}$ ) was measured with an automatic fluorimetric plate-reader (Fluoroskan Ascent) and readings were performed after 0, 30, 60, 120 and $180 \mathrm{~min}$ of incubation at $30^{\circ} \mathrm{C}$. The results were expressed as nmoles of product (MUF) of each enzymatic reaction released per $\mathrm{g}$ of soil per unit of time in relation to a standard curve prepared with increasing MUF concentrations and incubated at the same experimental conditions.

The community level physiological profile (CLPP) was determined using the MicroResp ${ }^{\mathrm{TM}}$ soil respiration system (James Hutton Ltd, Aberdeen, UK) according to Campbell et al. (2003).

The 15 substrates used for MicroResp were: $\alpha$-D-glucose, DGalactose, D-fructose, L-arabinose, L-leucine, L-arginine, Glycine, L-aspartic acid, $\gamma$-amino-butyric and glutamic acid, three carboxylic acids: citric acid, oxalic acid and L-ascorbic acid, and two phenolic acids: vanillic and syringic acid. The emission of $\mathrm{CO}_{2}$ by the microbial biomass was estimated using a colorimetric method (microplate spectrophotometer) before and after $6 \mathrm{~h}$ of incubation at $28^{\circ} \mathrm{C}$. The absorbance was read at $595 \mathrm{~nm}$. At the end the absorbance was normalised for any difference recorded at time zero and then converted to $\% \mathrm{CO}_{2}$ using the formula $\mathrm{y}=\mathrm{A}+\mathrm{B} /(1+\mathrm{D} \times \mathrm{Ai})$ where $\mathrm{Ai}$ is the normalised $6 \mathrm{hr}$ data. The formula is for a linear-to-linear (rectangular hyperbola) standard curve fit obtained by means of a calibration procedure taking into account the spectrophotometer used, the different soils and incubation conditions as reported in the MicroResp technical manual. In our experimental conditions the constants of the equation were: A: $-1,62$, B: $-4,85$ and D: $-8,1$. The $\% \mathrm{CO}_{2}$ was converted to $\mu \mathrm{g} \mathrm{C}-\mathrm{CO}_{2} \mathrm{~g}^{-1} \mathrm{~h}^{-1}$ production rate using gas constant, $\mathrm{T}{ }^{\circ} \mathrm{C}$, headspace volume, soil dry weight (d.w.) and incubation time. The SEI (Synthetic Enzymatic Index) and SIR (Substrate Induced Respiration) for all soils within the three categories (F, A and EC) have been calculated as synthetic measures of microbial functional capacity. Both SEI and SIR represent the total microbial functional capacity expressed as sum of all enzymatic activities and of induced respiration of all substrates, respectively.

Microbial functional diversity was assessed calculating the Shannon diversity index (Kennedy and Smith, 1995) corresponding to the entropy concept defined by: $\mathrm{H}^{\prime}=-\Sigma \mathrm{p}_{\mathrm{i}} * \ln \mathrm{p}_{\mathrm{i}}$ (Shannon and Weaver, 1949; Spellerberg and Fedor, 2003), where $\mathrm{p}_{\mathrm{i}}$ is in turn: for H'EA, the ratio of the activity of a particular enzyme to the sum of all enzymatic activities while for H'MR it is the ratio of the respiration rate of each single C-substrate to the sum of all substrates. Shannon diversity index is related to the entropy of a system and when applied as a measure of microbial functions entropy, may express the heterogeneity of soil organic substrates availability and microbial processes (Marinari et al., 2013). Since the eight enzymes and the 15 substrates here tested did show activity in all the analysed samples, then, in this work, the diversity recorded reflects only the "evenness" or distribution of the enzyme activities or ability to use the different substrates (Bending et al., 2002; Rodríguez-Loinaz et al., 2008).

\subsection{Statistical analyses}

The analysis of all collected data was carried out into various steps. At first, with the aim to compare the two indexes, a standardization due to the existing differences in the range of H'EA and H'MR possible/ admissible values was performed by transforming the original indexes into two new variables each one with mean equal to zero and variance equal to 1 . As usual, the procedure was carried out by subtracting the variable mean (i.e. the mean value of H'EA and H'MR, respectively) from each observation and then dividing by its own standard deviation (each one obtained from the original indexes). As a property of standardized (z-scores) values, the standardized distributions maintain the same shape (i.e. in terms of skewness and kurtosis) of the two original distributions and the transformation does not change the location of any observation score relative to others in the distribution. From now on, all the statistical analyses were carried out on the two standardized distributions.

The descriptive analyses provided a clear picture of the distribution of the two indexes (H'EA and H'MR) as well as information about the shape of the two distributions. Moreover, rank correlation measures and test performed by using the Spearman correlation enabled to evaluate if, and to what extent, the two methodological approaches (EA, enzyme activities and MR, MicroResp ${ }^{\mathrm{TM}}$ ) used to evaluate soil microbial functional diversity are related.

The Kruskal-Wallis non-parametric test was used to test if and to what extent the two indexes distinguished the various land use categories in relation to TOC and $\mathrm{pH}$ ranges.

By considering the asymmetry of the two distributions (e.g. standardized H'EA and H'MR respectively, as shown in Fig. 2) as well as the results of the Shapiro-Wilk normality test, we analysed the existence of association between each of the two measures and selected covariates by using Quantile Regression Models (QRMs). In fact, these types of regression models offer the possibility to highlight how the effect of the selected covariates, in this case TOC content, $\mathrm{pH}$ and land use category, changes throughout the entire distribution of the dependent variable. To estimate the relationships (in terms of association) between the dependent variables and the set of selected covariates, the classical OLS (Ordinary Least Squares) regressions could be applied. However, data obtained from experimental collection tend to be skewed so that these models were not able to describe the "correct" relationships. Moreover, QRMs are more robust to the presence of outliers and can be consistent under weaker stochastic assumption than with least-squares estimation (Cameron and Trivedi, 2005; Koenker, 2005).

Referring to the soil context, the application of QRMs has important advantages. Firstly, QRMs can help to explore if the existing differences observed between the two measures can be attributed to different effects played by the explanatory variables at the various quantiles. Secondly, it can be interesting to understand what happens throughout the entire distribution of the two measures (H'EA and H'MR) and at their extremes.

We estimated two QRMs which assumed the dependent variable to be: (i) H'EA and (ii) H'MR respectively. In both models the set of covariates includes factors describing: the land use category (distinguished into Forest, Agricultural and Extreme soil Conditions), the levels of $\mathrm{pH}$ and TOC. Among the soil properties that mostly affect microbial biomass activity and diversity, TOC and $\mathrm{pH}$ were chosen as covariates to explain H' index variability (Creamer et al., 2016b; Fierer and Jackson, 2006; Constancias et al., 2015). In this study, soils were grouped into three categories in relation to TOC content: i) low: for TOC $<1.5 \%$; ii) medium TOC $<1.5-3>$; iii) high: for TOC $\geq 3 \%$. Similarly, soils were grouped into three categories in relation to $\mathrm{pH}$ values: i) $<6.5$ slightly acid - very strongly acid, ii) $<6.5-7.4>$ neutral, iii) $>7.4$ slightly alkaline - moderately alkaline. STATA software (STATA 13.2 edition) was used for statistical analyses. Three distinct levels of significance were considered for the estimated coefficients and are reported in the model: a value of $\mathrm{p}<0.001$ (indicated in the tables of results with 


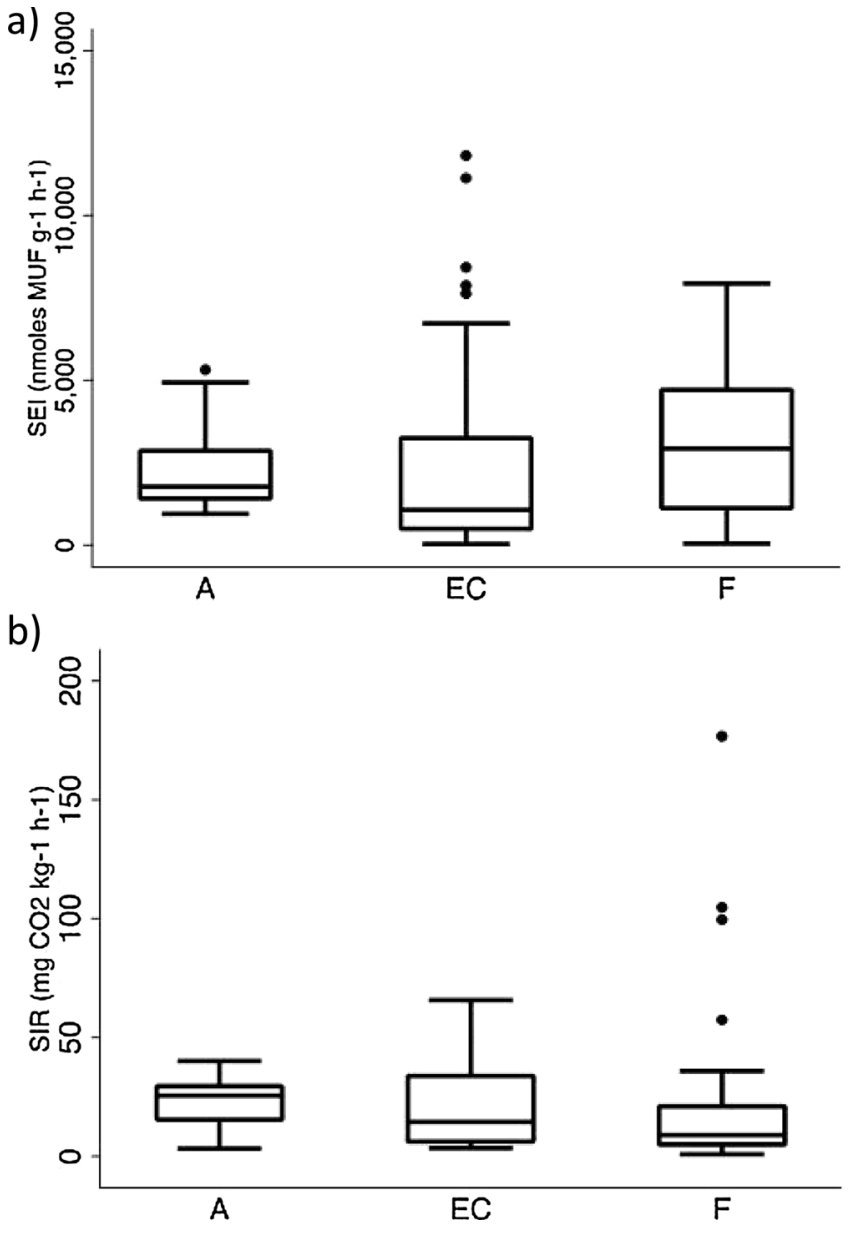

Fig. 1. Boxplot of microbial functional capacity measured by means of enzyme activities and CLPP-MicroResp. a) SEI (synthetic enzymatic index) and b) SIR (substrate induced respiration) distributions in the three soil categories (F, forest, A,agricultural and EC, extreme conditions soils).

$* * *)$, emphasizing strong relationships between the explicative variable of interest and the dependent variable significant at $0.1 \%$ level; the value of $\mathrm{p}<0.01$ (indicated in tables of results with $* *$ ) indicates a relationship significant at $1 \%$ level and finally a value of $p<0.05$ (indicated in the tables of results with *) emphasizing a relationship between the variables significant at $5 \%$ level.

\section{Results}

Fig. 1 shows the functional capacity of soil microbial biomass calculated as the SEI and SIR for all soils within the three categories (F, A and EC). Soils characterized by extreme conditions showed the highest level of variability - including upper outliers - for SEI (ranging from 42 to 11,800 nmoles MUF $\mathrm{g}^{-1} \mathrm{~h}^{-1}$ ), while the functional capacity of forest soils showed a high level of dispersion for SIR (ranging from 0.9 to $177 \mu \mathrm{g} \mathrm{CO}_{2} \mathrm{~g}^{-1} \mathrm{~h}^{-1}$ ). Agricultural soils show, for both methodological approaches, a smaller level of variability.

Fig. 2 shows the distribution of the two standardized indexes values H'EA and H'MR, respectively, over the 196 values of microbial functional diversity. The two distributions (expressed in terms of z-scores) are positively skewed and leptokurtic - as emerged by the descriptive statistics reported in Table 2 - and significantly different from normality as confirmed by the Shapiro-Wilk W and Shapiro-Francia W' test.

The Spearman rank correlation, verifying the similarity of the orderings of the data when ranked according to each of the measures, showed that the two measures are not related for measuring microbial functional diversity $(p$-value $=0.0987) \quad($ Table 3$)$. However, by
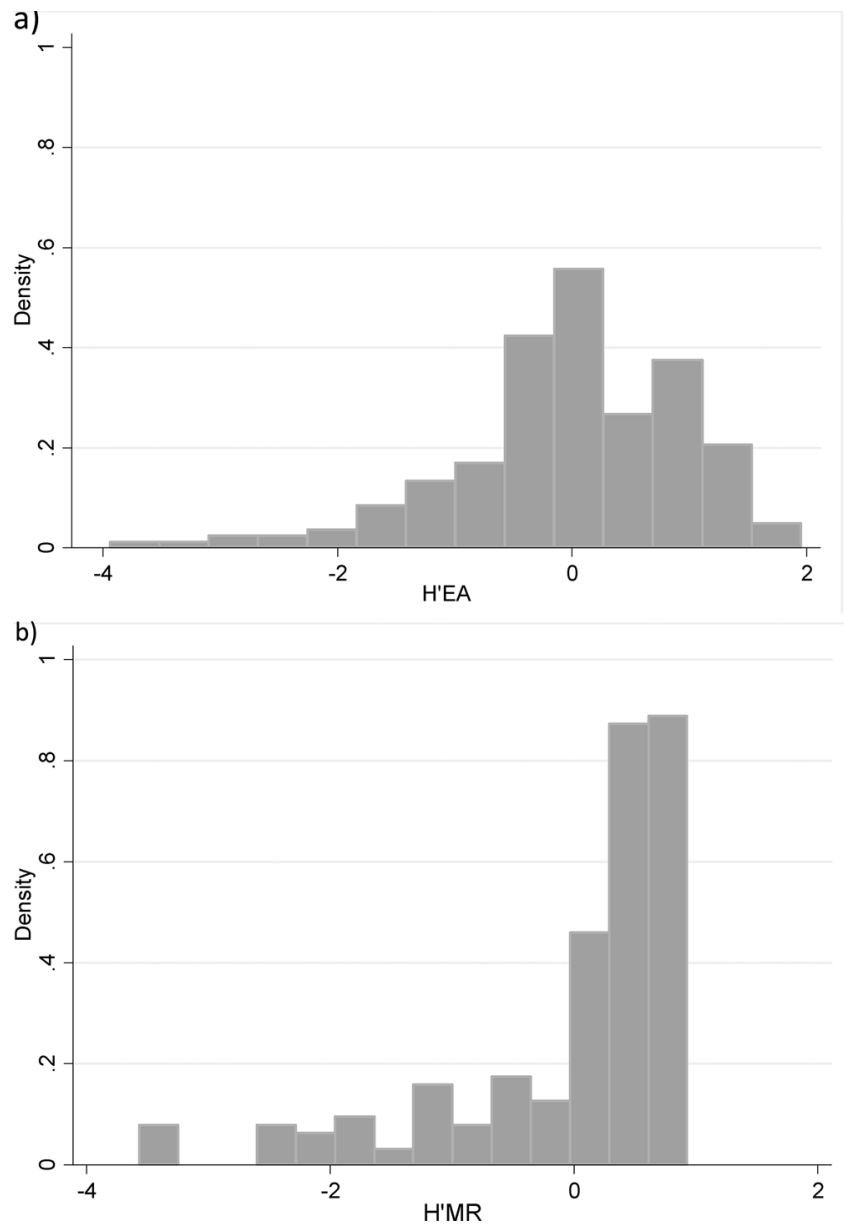

Fig. 2. Distribution of the two standardized indexes: a)H'EA and b) H'MR.

Table 2

Descriptive statistics of the two standardized measures. H'EA and H'MR: Shannon diversity index calculated by means of enzyme activities and MicroResp, respectively, over 196 soil samples.

\begin{tabular}{llllllll}
\hline Measure & Min & q0.25 & q0.50 & q.0.75 & Max & Skewness & Kurtosis \\
\hline H'EA & -3.940 & -0.451 & 0.039 & 0.754 & 1.953 & -0.851 & 4.279 \\
H'MR & -3.567 & -0.242 & 0.382 & 0.651 & 0.933 & -1.746 & 5.506 \\
\hline
\end{tabular}

Table 3

Spearman $r_{s}$ values for both standardized indices H'EA and H'MR calculated for all data and within the three soil categories F, A and EC soils. ns: not significant, **p $<0.01$.

\begin{tabular}{lllll}
\hline & All data & (F) & (A) & (EC) \\
\hline H'EA - H'MR & $-0.1183 \mathrm{~ns}$ & $-0.0273 \mathrm{~ns}$ & $-0.3180^{* *}$ & $-0.0482 \mathrm{~ns}$ \\
\hline
\end{tabular}

distinguishing rank correlation according to the land use category, we found a moderate and significant level of inverse rank correlation ( $p$ value $=0.0073$ ) when the two indexes refer to soil of type A. No significant rank correlation was found between the two measures for soil type EC and $\mathrm{F}$ ( $p$-value $=0.6534$ and $p$-value $=0.8727$ respectively) (Table 3).

According to the results of Kruskal-Wallis test, both H'EA and H'MR distinguished in different ways the various soils when TOC or $\mathrm{pH}$ ranges were considered (Table 4). Thus, according to the obtained $p$-values H'MR showed a slightly higher discriminatory potential than H'EA. H'MR, in fact, was significantly effective at low TOC ranges $(<1.5 \%)$ where H'EA was not. On the other hand, both methods failed to discriminate in alkaline soils ( $\mathrm{pH}$ values $\geq 7.4$ ). 
Table 4

Results of Chi-squared statistics $\mathrm{X}^{2}$ and $p$-values obtained with Kruskal-Wallis rank test on soil microbial functional diversity indices (H'EA and H'MR) among the three land use categories within restricted classes of total organic carbon (TOC) and $\mathrm{pH}$. P values are reported in parentheses.

\begin{tabular}{lll}
\hline TOC values & H'EA & H'MR \\
\hline Low: TOC $<1.5 \%$ & $2.202(0.333)$ & $11.039(0.004)$ \\
Medium: $1.5 \leq$ TOC $<3 \%$ & $7.640(0.022)$ & $6.272(0.043)$ \\
High: TOC $\geq 3 \%$ & $4.431(0.035)$ & $7.150(0.007)$ \\
\hline pH values & & \\
\hline$p H<6.5$ & $11.843(0.003)$ & $8.971(0.011)$ \\
$6.5 \leq p H<7.4$ & $13.867(0.001)$ & $30.998(0.000)$ \\
$p H \geq 7.4$ & $1.046(0.306)$ & $2.517(0.113)$ \\
\hline
\end{tabular}

Table 5

Estimation results of quantile regression models (QRMs) between soil microbial functional diversity indices ( $\mathrm{H}^{\prime} \mathrm{EA}$ and $\mathrm{H}^{\prime} \mathrm{MR}$ ) and the selected variables (land use category: forest soils - F, agricultural soils - A, extreme conditions soils - EC; $\mathrm{pH}$ and total organic carbon ranges) at quantiles $0.25,0.50,0.75 . \mathrm{SE}=$ standard error, * Significant at $5 \%$, ** $1 \%$ and $* * * 0.1 \%$ level.

\begin{tabular}{|c|c|c|c|c|c|c|}
\hline & \multicolumn{3}{|l|}{ H'EA } & \multicolumn{3}{|l|}{ H'MR } \\
\hline & Coef. & $S E$ & Sign. & Coef & $S E$ & Sign. \\
\hline \multicolumn{7}{|l|}{ Quantile 0.25} \\
\hline \multicolumn{7}{|l|}{ Low: $<1.5 \%)$} \\
\hline Medium: $1.5 \leq$ TOC $<3$ & 0.027 & 0.120 & & 0.505 & 0.338 & \\
\hline High: TOC $\geq 3 \%$ & 0.004 & 0.150 & & 0.744 & 0.436 & \\
\hline \multicolumn{7}{|l|}{ pH (ref. $\mathrm{pH}<6.5$ ) } \\
\hline $6.5 \leq \mathrm{pH}<7.4$ & -0.177 & 0.077 & $* *$ & 0.295 & 0.183 & \\
\hline $\mathrm{pH} \geq 7.4$ & -0.871 & 0.254 & $* *$ & -0.471 & 0.343 & \\
\hline \multicolumn{7}{|l|}{ Land use category (ref. EC) } \\
\hline $\mathrm{F}$ & 0.462 & 0.160 & $* *$ & 0.821 & 0.417 & \\
\hline A & 0.193 & 0.175 & & 0.996 & 0.497 & * \\
\hline Constant & -0.487 & 0.125 & $* * *$ & -1.276 & 0.426 & $* *$ \\
\hline \multicolumn{7}{|l|}{ Quantile 0.50} \\
\hline \multicolumn{7}{|c|}{ TOC values (ref. Low: $<1.5 \%$ ) } \\
\hline Medium: $1.5 \leq$ TOC $<3$ & -0.197 & 0.183 & & -0.043 & 0.097 & \\
\hline High: TOC $\geq 3 \%$ & -0.583 & 0.340 & & -0.0 .31 & 0.271 & \\
\hline \multicolumn{7}{|l|}{$\mathrm{pH}($ ref. $\mathrm{pH}<6.5$ ) } \\
\hline $6.5 \leq \mathrm{pH}<7.4$ & 0.066 & 0.259 & & 0.213 & 0.088 & * \\
\hline $\mathrm{pH} \geq 7.4$ & 0.417 & 0.342 & & -0.060 & 0.176 & \\
\hline \multicolumn{7}{|l|}{ Land use category (ref. EC) } \\
\hline $\mathrm{F}$ & 0.415 & 0.305 & & 0.418 & 0.230 & \\
\hline A & -0.377 & 0.180 & * & 0.259 & 0.114 & $*$ \\
\hline Constant & 0.260 & 0.307 & & 0.171 & 0.120 & \\
\hline \multicolumn{7}{|l|}{ Quantile 0.75} \\
\hline \multicolumn{7}{|c|}{ TOC values (ref. Low: $<1.5 \%$ ) } \\
\hline Medium: $1.5 \leq$ TOC $<3$ & -0.001 & 0.142 & & 0.008 & 0.072 & \\
\hline High: TOC $\geq 3 \%$ & -0.549 & 0.256 & * & -0.070 & 0.136 & \\
\hline \multicolumn{7}{|l|}{$\mathrm{pH}($ ref. $\mathrm{pH}<6.5)$} \\
\hline $6.5 \leq \mathrm{pH}<7.4$ & -0.008 & 0.233 & & 0.079 & 0.073 & \\
\hline $\mathrm{pH} \geq 7.4$ & 0.527 & 0.235 & * & -0.096 & 0.116 & \\
\hline \multicolumn{7}{|l|}{ Land use category (ref. EC) } \\
\hline $\mathrm{F}$ & 0.422 & 0.192 & $* *$ & 0.239 & 0.111 & $*$ \\
\hline A & -0.703 & 0.136 & $* * *$ & 0.160 & 0.080 & $*$ \\
\hline Constant & 0.804 & 0.246 & $* *$ & 3.212 & 0.414 & $* *$ \\
\hline
\end{tabular}

Notes: ${ }^{*} \mathrm{p}<0.05 ; * * \mathrm{p}<0.01 ; * * \mathrm{p}<0.001$.
The analysis of the potential relationships between each of the measures (H'EA and H'MR) and the selected variables (land use, TOC and $\mathrm{pH}$ ) was carried out by referring to the quantile regression model (QRM), which enabled analysis of the effect of the covariates throughout the entire distribution as well as at the extremes. Table 5 shows the estimation results of regression models at quantiles 0.25 , 0.50 and 0.75 .

Focusing on TOC content we only found a negative association at quantile 0.75 ( $p$-value < 0.05) between H'EA and high level of TOC (equal or greater than $3 \%$ ). On the other hand, $\mathrm{pH}$ levels are negatively related to the H'EA measure in the lower part of the distribution (e.g at quantile 0.25 of the dependent variable H'EA, $p$-value $<0.01$ ) while a positive relationship was observed with high levels of $\mathrm{pH}$ in the highest quantile of the distribution (e.g. for high values of the dependent variable H'EA). Furthermore, a positive relationship was found between medium level of $\mathrm{pH}$ (values ranging between 6.5 and 7.4) and H'MR in the middle part of the distribution (quantile 0.50).

The land use category is a key factor distinguishing the values of the two measures. For H'EA the relationship is positive and strongly significant at quantiles 0.25 and 0.75 for land use category F (forest soils) while a negative relationship with agricultural land use category was observed at quantiles 0.50 and 0.75 . At the same time, we observed positive and significant relationships between the values of H'MR and agricultural land use category at all different quantiles throughout the entire distribution while forest soil only at 0.75 quantile (Table 5).

\section{Discussion}

In this study, a large data set of 196 values of Shannon diversity index, calculated from data of enzyme activities and CLPP-MicroResp techniques, was used. Griffiths et al. (2016) recently included both techniques in a list of 18 potential, powerful indicators aimed to monitor soil biodiversity and ecosystem function across Europe.

The first aim of this paper was to assess the relative sensitivity of each methodological approach in capturing differences among the land use categories when different levels of $\mathrm{pH}$ and TOC are considered.

The Kruskal-Wallis test showed that both methods were able to highlight differences among land use categories at almost all ranges of TOC and $\mathrm{pH}$. However, while both of them failed to discriminate in alkaline soils ( $\mathrm{pH}>7.4)$, only MicroResp was completely effective along the whole TOC gradient, including low TOC values $(<1.5 \%)$. This result might point to MicroResp as a more powerful tool for evaluating microbial functional diversity, particularly in oligotrophic environments where the addition of easily available organic $C$ sources (represented by the different substrates) may stimulate microbial respiration. Conversely, enzyme production is not similarly stimulated as it requires a higher energetic expense (Burns and Dick, 2002). In studies aimed to evaluate the effect of land use change on microbial functional diversity, the CLPP-MicroResp approach can be thus suggested as soil microbial catabolic evenness among various land-uses is usually related to differences in organic C pools (Degens et al., 2000). Creamer et al. (2009) also reported that the MSIR (multi substrate induced respiration) technique resulted in a much more distinct and relatively consistent pattern of separation between the tested soils with respect to enzyme activities. The lack of potential for both techniques to discriminate among different land uses in alkaline soils $(\mathrm{pH}>7.4)$ may be due to the fact that the interrelationship between soil $\mathrm{pH}$ and microbial diversity may be lost (Fierer and Jackson, 2006) or even decreased (Griffiths et al., 2011) at soil pH values higher than 7.

In this study, no correlation was found between H'EA and H'MR all over the data collected. Moreover, an opposite behaviour of the two indexes was found in agricultural soils where the significant $(\mathrm{p}<0.01)$ correlation coefficient was negative. This result confirms what was previously observed regarding oligotrophic environments characterized by lower organic matter content, such as agricultural soils. In fact, as reported by Lagomarsino et al. (2011), the microbial functional 
diversity determined by means of the enzymatic pattern is affected by land use showing an increase along a gradient of soil organic matter. In the same paper the authors reported an inverse relationship between microbial functional diversity and the catabolic response per unit of biomass expressed by the metabolic quotient $\left(q \mathrm{CO}_{2}\right)$.

The lack of correlation between H' by means of enzymes and CLPPMicroResp suggests that the two techniques may assess sequential steps of decomposition processes, even if in this meta-analysis the product of most selected enzymatic reactions did not represent the substrates used to test CLPP-MicroResp. Enzymatic hydrolysis focuses on the breakdown of complex organic polymers, which not necessarily leads to the complete mineralization of substrates but can also lead to anabolic pathways for biosynthetic processes, polymerization, condensation (e.g. humification, interaction with mineral colloids). Conversely, CLPPMicroResp measures the complete mineralization of simple and complex organic compounds to $\mathrm{CO}_{2}$, which represents the final step of decomposition process. Therefore, in our opinion, a comprehensive assessment of microbial functional diversity can be provided by the integration of both techniques. For this reason, they can be considered complementary components of microbial functional diversity.

Moreover, to further explain the lack of correlation between the two methods, we should keep in mind that soil enzymes include the contribution, considerable in most cases, of the immobilized fraction (humus-clay bound enzymes) (Nannipieri et al., 2012). This fraction is considered a permanent bio-catalytic property of the soil, not necessarily linked to the living biomass. Immobilized enzymes may represent soils' background hydrolytic potentials, established and stabilized during time, and representing their resilient capacity (Ceccanti et al., 2008). To date, no methods are available to distinguish between the extracellular activities of stabilized enzymes from that of enzymes associated with active cells. Such separation is important because only enzymes associated with active cells contribute to microbial activity. The stabilized extracellular fraction is no more related to microbial metabolism and can persist in soil under unfavourable conditions for soil microorganisms (Nannipieri et al., 2012). Therefore, enzyme activities, and the functional diversity measures derived from using this methodology, inform on the general soil biological functioning including not only the actual living microbial activity but also the past biochemical activity still operating within soil matrix. Conversely, CLPP-MicroResp has been considered a direct measurement of microbial communities' catabolic profile providing an instant photograph of microbial physiology (Lagomarsino et al., 2007).

The QRM helped to understand if, and to what extent, the role of selected covariates (land use, TOC and $\mathrm{pH}$ ) changes throughout the entire distribution of each dependent variable (H'EA and H'MR). It is, in fact, known that microbial functions are largely dependent on organic substrates availability and soil reaction (Bardgett and van der Putten, 2017). The QRM was found to be an effective statistical approach to analyse microbial functional diversity response in relation to the selected covariates, particularly at the lowest $(0.25)$ and highest $(0.75)$ quantiles.

In this study QRM showed that both diversity indexes depended more on soil $\mathrm{pH}$ than on TOC content indicating soil reaction as the property mostly affecting microbial diversity (Zhalnina et al., 2014). In fact, only when TOC values were above $3 \%$ the H'EA was negatively affected suggesting that the increase of soil available organic compounds may cause a negative feedback on microbial hydrolytic reactions. On the contrary, it was more evident the relationship between $\mathrm{pH}$ and both indices. H'EA was negatively related to $\mathrm{pH}$ in the 0.25 quantile indicating that low levels of this index are more sensitive to soil $\mathrm{pH}$ variations (Griffiths et al., 2011). Conversely the dependence of both indexes ( $\mathrm{H}^{\prime} \mathrm{MR}$ and $\mathrm{H}^{\prime} \mathrm{EA}$ ) on $\mathrm{pH}$ was positive at 0.50 , and 0.75 quantiles, respectively. Soil $\mathrm{pH}$ variations can induce, more than the mere TOC content, significant changes within microbial biomass structure in terms of species and related functional patterns. Microbial biochemical processes are strictly dependent on $\mathrm{pH}$ values that control the majority of the reactions occurring in the soil. Fierer and Jackson (2006) and Lemanceau et al. (2015) reported soil pH as the best predictor of microbial diversity and richness affecting consequently microbial functions.

However, the nature of this relationship is controversial. Griffiths et al. (2011) report that a decline of $\beta$-diversity was observed at increasing $\mathrm{pH}$ in a spatial assessment of soil bacterial community profiles across Great Britain. Fierer and Jackson (2006), in a similar study performed across North and South America, showed a unimodal distribution of bacterial diversity, reaching possibly a plateau at near neutral $\mathrm{pH}$.

Finally, the influence of the different land use categories was evident in some parts of the distribution for both indexes, especially at 0.75 quantile. In particular, the effect of forest soils was always positive, in most cases significant, for both indexes at all quantiles, confirming the strict relationship existing between the forest environment and soil microbial diversity (Creamer et al., 2016b).

\section{Conclusions and future perspectives}

This study demonstrates that both methods, enzyme activities and MicroResp, are reliable ecological indicators to assess soil microbial functional diversity. However, since no correlation was found between the diversity indexes H'EA and H'MR, it was hypothesized that the two methods may target complementary components of microbial functional diversity.

The results lead to the following conclusions: $i$ ) both methods were effective in capturing differences among various land use categories although MicroResp was more sensitive at low levels of soil organic matter, ii) the QRM approach allowed a more detailed analysis along the distribution of the diversity indexes (H'EA and H'MR) with H'EA showing a more significant dependence on the selected variables.

This study can lay the foundations to further studies aimed to assign an ecological significance to the assessment of microbial functional diversity.

\section{Acknowledgements}

The authors wish to thank the following projects that funded the research: Italian Ministry for Education, University and Research MIUR, Research Projects of National Interest PRIN 2008 (20082FC352-002) and 2010 (2010JBNLJ7-006) the European Union FP7 Project n.289277: OSCAR (Optimising 423 Subsidiary Crop Applications in Rotations).

\section{References}

Adhikari, K., Hartemink, A.E., 2016. Linking soils to ecosystem services-a global review. Geoderma 262, 101-111.

Bardgett, R.D., van der Putten, W.H., 2014. Belowground biodiversity and ecosystem functioning. Nature 515, 505-511.

Bending, G.D., Turner, M.K., Jones, J.E., 2002. Interactions between crop residue and soil organic matter quality and the functional diversity of soil microbial communities. Soil Biol. Biochem. 34, 1073-1082.

Brunetti, P., 2014. Organic Mulching Impacts on Vegetable Crop Production. Environmental Sciences PhD Thesis. University of Tuscia.

Burns, R.G., Dick, R.P., 2002. Enzymes in the Environment Activity, Ecology, and Applications. Marcel Dekker, New York.

Cameron, A.C., Trivedi, P.K., 2005. Microeconometrics, Methods and Applications. Cambridge University Press.

Campbell, C.D., Chapman, S.J., Cameron, C.M., Davidson, M., Potts, J.M., 2003. A rapid microtiter plate method to measure carbon dioxide evolved from carbon substrate amendments so as to determine the physiological profiles of soil microbial communities by using whole soil. Appl. Environ. Microbiol. 69, 3593-3599.

Ceccanti, B., Doni, S., Macci, C., Cercignani, G., Masciandaro, G., 2008. Characterization of stable humic-enzyme complexes of different soil ecosystems through analytical isoelectric focussing technique IEF). Soil Biol. Biochem. 40 (9), 2174-2177.

Chapman, S.J., Campbell, C.D., Artz, R.R.E., 2007. Assessing CLPPs using MicroRespTM: a comparison with biolog and multi-SIR. J. Soils Sediments 7, 406-410.

Constancias, F., Saby, N.P., Horrigue, W., Villerd, J., Guillemin, J.P., Duval, L.B., Nowak, V., Dequiedt, S., Ranjard, L., Chemidlin Prevost-Bour, N., 2015. Mapping and 
determinism of soil microbial community distribution across an agricultural landscape. Microbiol. Open 4 (3), 505-517. http://dx.doi.org/10.1002/mbo3.255.

Creamer, R.E., Bellamy, P., Black, H.I., Cameron, C.M., Campbell, C.D., Chamberlain, P., Ritz, K., 2009. An inter-laboratory comparison of multi-enzyme and multiple substrate-induced respiration assays to assess method consistency in soil monitoring. Biol. Fertil. Soils 45 (6), 623-633.

Creamer, R.E., Stone, D., Berry, P., Kuiper, I., 2016a. Measuring respiration profiles of soil microbial communities across Europe using MicroRespTM method. Appl. Soil Ecol. 97, 36-43.

Creamer, R.E., Hannula, S.E., Van Leeuwen, J.P., Stone, D., Rutgers, M., Schmel, R.M., de Ruiter, P.C., Bohse Hendriksen, N., Bolger, T., Bouffaud, M.L., Buee, M., Carvalho, F., Costa, D., Dirilgen Francisco, T.R., Griffiths, B.S., Griffiths, R., Martin, F., Martin da Silva, P., Mendes, S., Morais, P.V., Pereira, C., Philippot, L., Plassart, P., Redecker, D., Römbke, J., Sousa, J.P., Wouterse, M., Lemanceau, P., 2016b. Ecological network analysis reveals the inter-connection between soil biodiversity and ecosystem function as affected by land use across Europe. Appl. Soil Ecol. 97, 112-124.

Degens, B.P., Schipper, L.A., Sparling, G.P., Vukovic, M.V., 2000. Decreases in organic C reserves in soils can reduce the catabolic diversity of soil microbial communities. Soil Biol. Biochem. 32, 189-196.

Delgado-Baquerizo, M., Maestre, F.T., Reich, P.B., Jeffries, T.C., Gaitan, J.J., Encinar, D., Berdugo, M., Campbell, C.D., Singh, B.K., 2016. Microbial diversity drives multifunctionality in terrestrial ecosystems. Nat. Commun. 7, 10541. http://dx.doi.org/10 1038/ncomms10541.

Emili, L., 2013. Soil Bioremediation Assessment In Heavy Metal Polluted Areas, ISBN 9783-639-62738-1 EAI (Edizioni Accademiche Italiane). OmniScriptum GmbH \& Co., KG Saarbrücken Germania.

Emmerling, C., Schloter, M., Hartmann, A., Kandeler, E., 2002. Functional diversity of soil organisms a review of recent research activities in Germany. J. Plant Nutr. Soil Sci. 165, 408-420.

Fierer, N., Jackson, R.B., 2006. The diversity and biogeography of soil bacterial communities. PNAS 103 (3), 626-631. http://dx.doi.org/10.1073/pnas.0507535103.

Garland, J.L., Mills, A.L., 1991. Classification and characterization of heterotrophic mi crobial communities on the basis of patterns of community-level sole-carbon- source utilization. Appl. Environ. Microbiol. 57, 2351-2359.

Griffiths, R.I., Thomson, B.C., James, P., Bell, T., Bailey, M., Whiteley, A.S., 2011. The bacterial biogeography of British soils. Environ. Microbiol. 13 (6), 1642-1654. http://dx.doi.org/10.1111/j.1462-2920.2011.02480.x.

Griffiths, B.S., Römbke, J., Schmelz, R.M., Scheffczyk, A., Faber, J.H., Bloem, J., Pérès, G., Cluzeau, D., Chabbi, A., Suhadolc, M., Sousa, J.P., Martins da Silva, P., Carvalho, F., Mendes, S., Morais, P., Francisco, R., Pereira, C., Bonkowski, M., Geisen, S., Bardgett, R.D., de Vries, F.T., Bolger, T., Dirilgen, T., Schmidt, O., Winding, A., Hendriksen, N.B., Johansen, A., Philippot, L., Plassart, P., Bru, D., Thomson, B., Griffiths, R.I., Bailey, M.J., Keith, A., Rutgers, M., Mulder, C., Hannula, S.E., Creamer, R., Stone, D., 2016. Selecting cost effective and policy-relevant biological indicators for European monitoring of soil biodiversity and ecosystem function. Ecol. Ind. 69, 213-223.

Hendriksen, N.B., Creamer, R.E., Stone, D., Winding, A., 2016. Soil exo-enzyme activities across Europe - the influence of climate, land-use and soil properties. Appl. Soil Ecol. 97, 44-48.

Insam, H., Parkinson, D., Domsch, K.H., 1989. Influence of macroclimate on soil microbial biomass. Soil Biol. Biochem. 21, 211-221.

Kennedy, A.C., Smith, K.L., 1995. Soil microbial diversity and the sustainability of agricultural soils. Plant Soil 170, 75-86.

Koenker, R., 2005. Quantile Regression. Cambridge University Press, New York.

Lagomarsino, A., Knapp, B.A., Moscatelli, M.C., De Angelis, P., Grego, S., Insam, H., 2007. Structural and functional diversity of soil microbes is affected by elevated $\mathrm{CO}_{2}$ and $\mathrm{N}$ addition in a poplar plantation. J. Soils Sed. 7, 399-405.

Lagomarsino, A., Benedetti, A., Marinari, S., Pompili, L., Moscatelli, M.C., Roggero, P.P., Lai, R., Ledda, L., Grego, S., 2011. Soil organic C variability and microbial functions in a Mediterranean agro-forest ecosystem. Biol. Fertil. Soil 47 (3), 283-291.

Lemanceau, P., Maron, P.A., Mazurier, S., Mougel, C., Pivato, B., Plassart, P., Ranjard, L., Revellin, C., Tardy, V., Wipf, D., 2015. Understanding and managing soil biodiversity: a major challenge in agroecology. Agron. Sustain. Dev. 35, 67-81. http://dx.doi.org/10.1007/s13593-014-0247-0.

Li, Z., Wu, X., Chen, B., 2007. Changes in transformation of soil organic C and functional diversity of soil microbial community under different land uses. Agric. Sci. China 6 (10), 1235-1245.

Marinari, S., Bonifacio, E., Moscatelli, M.C., Falsone, G., Vittori Antisari, L., Vianello, G., 2013. Soil development and microbial functional diversity: proposal for a methodological approach. Geoderma 192, 437-445.

Marx, M.C., Wood, M., Jarvis, S.C., 2001. A microplate fluorimetric assay for the study of enzyme diversity in soils. Soil Biol. Biochem. 33, 1633-1640.

Nannipieri, P., Ascher, J., Ceccherini, M.T., Landi, L., Pietramellara, G.P., Renella, G., 2003. Microbial diversity and soil functions. Eur. J. Soil Sci. 54, 655-670.

Nannipieri, P., Giagnoni, L., Renella, G., Puglisi, E., Ceccanti, B., Masciandaro, G., Fornasier, F., Moscatelli, M.C., Marinari, S., 2012. Soil enzymology: classical and molecular approachesl. Biol. Fertil. Soils 48, 743-762. http://dx.doi.org/10.1007/ s00374-012-0723-0.

Papp, R., Antisari, L.V., Vianello, G., Marabottini, R., Marinari, S., 2015. Soil microbial activity in hydromorphic-subaqueous ecosystems: processes and functional diversity. EQA Environ. Qual. Qualité de lEnvironnement/Qualità ambientale 18, 11-19.

Papp, R., 2016. Soil indicators set up to assess sustainable management in various agricultural and forest ecosystems. Pedology. PhD Thesis. University of Tuscia.

Pereira Silva, M.C., Semenov, A.V., Schmitt, H., van Elsas, J.D., Falcão Salles, J., 2013. Microbe-mediated processes as indicators to establish the normal operating range of soil functioning. Soil Biol. Biochem. 57, 995-1002.

Pignataro, A., Moscatelli, M.C., Mocali, S., Napoli, R., Grego, S., Benedetti, A., 2011. Preliminary investigation on soil microbial diversity: effect of pedogenetic substrate. EQA - Environ. Qual. /Qualité de l'Environnement/Qualità ambientale 7, 5-49 (ISBN 978-88-906735-9-7, ISSN 2039-9898).

Pignataro, A., Moscatelli, M.C., Mocali, S., Grego, S., Benedetti, A., 2012. Assessment of soil microbial functional diversity in a coppiced forest system. Appl. Soil Ecol. 62, $115-123$.

Rodríguez-Loinaz, G., Onaindi, M., Amezaga, I., Mijangos, I., Garbis, C., 2008. Relationship between vegetation diversity and soil functional diversity in native mixed-oak forests. Soil Biol. Biochem. 40, 49-60.

Rutgers, M., Wouterse, M., Drost, S.M., Breure, A.M., Mulder, C., Stone, D., Creamer, R.E. Winding, A., Bloem, J., 2016. Monitoring soil bacteria with community-level physiological profiles using Biolog ${ }^{\mathrm{TM}}$ ECO-plates in the Netherlands and Europe. Appl. Soil Ecol. 97, 23-35.

Shannon, C.E., Weaver, W., 1949. The Mathematical Theory of Communication. University of Illinois Press, Urbana, IL.

Spellerberg, I.F., Fedor, P.J., 2003. A tribute to Claude Shannon (1916-2001) and a plea for more rigorous use of species richness, species diversity and the 'Shannon-Wiener' Index. Global Ecol. Biogeog. 12, 177-179.

Stazi, S.R., Moscatelli, M.C., Papp, R., Crognale, S., Grego, S., Martin, M., Marabottini, R. 2017. A multi-biological assay approach to assess microbial diversity in arsenic (As). contaminated soils. Geomicrobiol 34 (2), 183-192. http://dx.doi.org/10.1080/ 01490451.2016.1189015.

Wellington, E.M.H., Berry, A., Krsek, M., 2003. Resolving functional diversity in relation to microbial community structure in soil, exploiting genomics and stable isotope probing. Curr. Opin. Microbiol. 6 (3), 295-301.

Wittmann, C., Kahkonen, M.A., Ilvesniemi, H., Kurola, J., Salkinoja-Salonen, M.S., 2004 Areal activities and stratification of hydrolytic enzymes involved in the biochemical cycles of carbon nitrogen, sulphur and phosphorus in podsolized boreal forest soils. Soil Biol. Biochem. 36, 425-433.

Zak, J.C., Willig, M.R., Moorhead, D.L., Wildman, H.D., 1994. Functional diversity of microbial communities: a quantitative approach. Soil Biol. Biochem. 26, 1101-1108.

Zhalnina, K., Dias, R., de Quadros, P.D., Davis-Richardson, A., Camargo, F.A.O., Clark, I.M., McGrath, S., Hirsch, P. R., Triplett, E.W., 2014. Soil pH determines microbial diversity and composition in the park grass experiment. Microb. Ecol. 69 (2), 395-406. 